DR. TIANNING PU (Orcid ID : 0000-0001-8106-0547)

Article type : Research Article

\title{
An in vitro DNA Phosphorothioate Modification Reaction
}

Tianning $\mathrm{Pu}^{1}$, Zhiling $\mathrm{Mei}^{2}$, Wei Zhang ${ }^{1}$, Wei-Jun Liang ${ }^{3}$, Xiufen Zhou ${ }^{1}$, Jingdan Liang ${ }^{*}$, Zixin Deng $^{1 *}$, and Zhijun Wang ${ }^{1 *}$

1, State Key Laboratory of Microbial Metabolism, School of Life Science and Biotechnology, Shanghai Jiao Tong University, Shanghai, People's Republic of China.

2, Shanghai Thinkgene Biotech CO., LTD, Shanghai, People's Republic of China.

3, Department of Life and Environmental Sciences, Faculty of Science and Technology, Bournemouth University, Talbot Campus, Fern Barrow, Poole, Dorset, United Kingdom, BH12 5BB

Running title: DNA Phosphorothioate Modification Reaction

* Corresponding authors:

This article has been accepted for publication and undergone full peer review but has not been through the copyediting, typesetting, pagination and proofreading process, which may lead to differences between this version and the Version of Record. Please cite this article as doi: 10.1111/MMI.14430

This article is protected by copyright. All rights reserved 
Zhijun Wang, Ph.D., Laboratory of Microbial Metabolism and School of Life Sciences \& Biotechnology, Shanghai Jiao Tong University, Shanghai 200030, CHINA, Tel/Fax: +86 21 62933765-2061(O), E.mail: wangzhijun@sjtu.edu.cn.

Jingdan Liang, Ph.D., Laboratory of Microbial Metabolism and School of Life Sciences \& Biotechnology, Shanghai Jiao Tong University, Shanghai 200030, CHINA, Tel/Fax: +86 21 62933765-2061(O), E.mail: jdliang@sjtu.edu.cn.

Zixin Deng, Ph.D., Laboratory of Microbial Metabolism and School of Life Sciences \& Biotechnology, Shanghai Jiao Tong University, Shanghai 200030, CHINA, Tel/Fax: +86 21 62933765-2061(O), E.mail: zxdeng@sjtu.edu.cn.

\section{Summary}

Phosphorothioation (PT) involves the replacement of a nonbridging phosphate oxygen on the DNA backbone with sulfur. In bacteria, the procedure is both sequence- and stereo-specific. We reconstituted the PT reaction using purified DndCDE from Salmonella enterica and IscS from E. coli. We determined that the in vitro process of PT was oxygen-sensitive. Only one strand on a doublestranded (ds) DNA substrate was modified in the reaction. The modification was dominant between $\mathrm{G}$ and $\mathrm{A}$ in the GAAC/GTTC conserved sequence. The modification between $\mathrm{G}$ and $\mathrm{T}$ required the presence of PT between G and A on the opposite strand. Cysteine, S-adenosyl methionine (SAM), and the formation of an iron-sulfur cluster in DndCDE (DndCDE-FeS) were essential for the process. Results from SAM cleavage reactions support the supposition that PT is a radical SAM reaction. ATP promoted the reaction but was not essential. The data and conclusions presented suggest that the PT reaction in bacteria involves three steps. The first step is the binding of DndCDE-FeS to DNA and searching for the modification sequence, possibly with the help of ATP. Cysteine locks DndCDE-FeS to the modification site with an appropriate protein conformation. SAM triggers the radical SAM reaction to complete the oxygen-sulfur swapping.

\section{Keywords}

phosphorothioate modification, S-adenosyl methionine (SAM), radical SAM reaction, iron-sulfur cluster, cysteine, sulfur incorporation. 


\section{Introduction}

Most FDA-approved oligonucleotide drugs incorporate phosphorothioate (PT) linkages for enhanced pharmacokinetic profiles. Many PT-containing candidates for various diseases are undergoing clinical evaluation. The advantages of PT are metabolic stability and improved cellular uptake due to its nuclease resistance. Efforts are made to control stereochemical variation introduced by PT linkages to improve pharmacologic properties of drugs. DNA PT modification occurs in bacteria, ranging from about $10 \%$ to $60 \%$ in different bacterial strains (Alonso et al., 2005; Wang et al., 2011; Wang et al., 2007; Zhou et al., 2005). The incorporation of sulfur in this manner endows the PT-modified DNA with altered redox and nucleophilic properties (Xie et al., 2012), providing it a special ability to be involved in complicated biological functions, such as antioxidation, restrictionmodification, virus defense, gene transcriptional control, and the maintenance of cellular redox homeostasis (Chen et al., 2017; Kellner et al., 2017; Ray et al., 1995; Tong et al., 2018; Wang et al., 2018; Wu et al., 2017; Xie et al., 2012; Xiong et al., 2019; Xu et al., 2010; Yang et al., 2017).

Since the discovery of PT modification in bacteria (Zhou et al., 1988; Zhou et al., 2005), a longsought goal has been determining the mechanisms that are involved in the incorporation of sulfur into the DNA phosphate backbone. Preliminary bioinformatical and biochemical suggestions have indicated how it occurs (You et al., 2007; Zhou et al., 2005). The enzyme involved in PT was identified as a four-protein complex, IscS-DndCDE (Cao et al., 2015; Xiong et al., 2015). IscS is a cysteine desulfurase that catalyzes the reconstitution of the [Fe-S] cluster in DndC (An et al., 2012; You et al., 2007). The DndD protein shows high similarity to SMC (structural maintenance of chromosomes) proteins. Both DndC and DndD hydrolyze ATP (Yao et al., 2009; You et al., 2007) and DndE has a tetrameric form that preferentially binds to nicked DNA (Hu et al., 2012). Based on these information, it has been hypothesized that the incorporation of sulfur into the DNA backbone involves the nicking of double-stranded (ds) DNA, and the consumption of energy (Eckstein, 2007;

Zhou et al., 2005). PT has also been studied in vitroin an attempt to better understand the sequence recognition process (Cao et al., 2015).

Here, we report detailed findings from experiments conducted to investigate and characterize the biochemical activity(ies) of the cloned recombinant PT protein complex from Salmonella enterica 
serovar Cerro 87 in vitro and in vivo under both oxic (DndCDE) and anoxic (DndCDE-FeS) conditions. We observed that when the protein complex was prepared under anoxic conditions, PT modification activity actually occurred. The PT activity of the protein could not be observed when the protein was prepared under oxic conditions or when the Fe-S cluster was disrupted. Furthermore, Sadenosyl-L-methionine (SAM) is essential for the PT modification reaction. Overall, our results suggest that PT modification occurs by a radical SAM reaction.

\section{Results}

\section{DNA PT modification by DndCDE and DndCDE-FeS.}

In a previous in vitro investigation where others looked at phosphorothioate modification of DNA, recombinant DndCDE recovered by a one-step nickel affinity column purification from a total cellular extract of E. coli BL21 (Cao et al., 2015) was used. Although PT activity was detected, key questions such as the mechanism of activation of the DNA backbone (Eckstein, 2007) and the role of and requirement for cofactors involved in the reaction were not addressed. To carry out the investigation, we needed to determine the best conditions for the promotion of PT, and in initial experiments, we employed DndCDE purified to homogeneity using a three-step protocol ( $\mathrm{Pu}$ et al., 2019; Xiong et al., 2015). Unfortunately, when we mixed DndCDE with IscS, ATP, cysteine, substrate DNA, $\mathrm{Mg}^{2+}$ and pyridoxal phosphate to initiate the PT reaction, no PT activity was observed by HPLC-MS. Given the other data reported so far (Pu et al., 2019), we suspected that the integrity of the Fe-S cluster of the DndCDE could have been compromised during its oxic purification, and to see if this was the case we then generated DndCDE-FeS and used it in anoxic PT assays; these assays still did not produce PT activity.

Recently, we showed that the Fe-S cluster of DndC is in the [4Fe-4S] configuration ( $\mathrm{Pu}$ et al., 2019). The cluster has a $g$ value peak of 2.005 at $13 \mathrm{~K}$. The cluster can be deprived off by $\alpha, \alpha^{\prime}-$ dipyridyl treatment and reconstituted back using cysteine and $\left(\mathrm{NH}_{4}\right)_{2} \mathrm{Fe}\left(\mathrm{SO}_{4}\right)_{2}$ with the catalysis of IscS under anoxic conditions (Fig. S2). The [4Fe-4S] cluster in the radical SAM type enzymes (Mulliez et al., 2017) mediates their radical reaction. We thus added SAM to the PT reaction mixture. The canonical dGsA mass signal was successfully observed (Fig. 1A(i)). Consequently, this in vitro anoxic reaction allowed us to analyze the contribution of individual cofactors to the PT reaction. From

This article is protected by copyright. All rights reserved 
these experiments, it was clear that SAM, cysteine and ATP were all required for the reaction to proceed (Fig. 1A(i)). Without the presence of ATP, the PT activity of DndCDE-FeS significantly decreased, yet ATP was not essential to the reaction (Fig. 1A(i)). Fe-S cluster involvement in PT was reconfirmed by treating DndCDE-FeS with $\alpha, \alpha^{\prime}$-dipyridyl, which abolished this activity (Fig. 1B(i)). PT occurred under only strictly anoxic conditions, and the oxic addition of SAM into the reaction mixture failed to promote PT even with anoxically generated DndCDE-FeS.

It is well reported that PT modification in vivo involves 4 bp of substrate DNA (Liang et al., 2007; Wang et al., 2011) and that in the cases of E. coli and S. enterica, the core conserved sequence involved is GAAC/GTTC (Wang et al., 2011). It is also known that no significant flanking sequence preferences appear to be involved in the specific site modification that occurs during PT (Cao et al., 2014). Finally, in vivo PT occurs as a ds DNA modification with both strands thought to be modified simultaneously (single-stranded (ss) modification has also been observed (Cao et al., 2014)). Consequently, we imagined that in our experiments, we would make similar observations, and we were surprised when, as part of our general investigation of PT and during the optimization of the assay described in the Experimental procedures, this was not the case. The dGsT formation was not observed in the PT reaction (Fig. 1A(ii) and Fig. 1B(ii)).

\section{DndC in DndCDE-FeS probably represents a new family of radical SAM enzymes}

The N-terminal region of DndC (from residue 1 to 300) shows similarity to the sequences of adenosine 5'-phosphosulfate reductase (APS reductase) (27\% identity to APS reductase from Pseudomonas aeruginosa) and phosphoadenosine phosphosulfate reductase (PAPS reductase) (20\% identity to PAPS reductase from E. coli) (Fig. S1), which all belong to the CysH superfamily. Both PAPS reductase and APS reductase are not radical SAM type enzyme (see below). The crucial difference between APS reductase and PAPS reductase is that APS reductase contains a [4Fe-4S] cluster, while PAPS reductase does not. In the Pseudomonas aeruginosa APS reductase, the four cysteine residues at positions 139, 140, 228 and 231 are responsible for the ligation of the [4Fe-4S] cluster. It is noteworthy that three of the cysteine residues (C146, C280, and C283) are conserved between DndC and the APS reductases (Fig. S1). In DndC, these three cysteine residues are also involved in the $[4 \mathrm{Fe}-4 \mathrm{~S}]$ coordination (Pu et al., 2019), while the fourth cysteine residue is absent

This article is protected by copyright. All rights reserved 
from DndC proteins. There are additional two cysteine residues $\left(\mathrm{C}_{262}\right.$ and $\left.\mathrm{C}_{273}\right)$ that are absent from APS reductase.

The radical SAM superfamily (RSS) contains a tremendous number of homologous enzymes that catalyze a remarkably broad range of reactions (Lanz \& Booker, 2015; Wang et al., 2014). They exhibit varied and complex domain architectures. The lengths of the RSS functional domains range from 46 to 1449 residues (Holliday et al., 2018). Three characteristics are minimally required for an enzyme to be considered a radical SAM enzyme: a unique three-cysteine motif that ligates the [4Fe$4 \mathrm{~S}$ ] cluster, with the apical iron free to bind the SAM moiety; a common activation step involved in the generation of the 5'-deoxyadenosyl (5'-dA) radical (SAM reductive cleavage); and reduction of the $[4 \mathrm{Fe}-4 \mathrm{~S}]$ cluster by an external electron donor.

DndC protein from $S$. lividans was previously shown to contain a 4Fe-4S cluster (You et al., 2007). We characterize recently the $4 \mathrm{Fe}-4 \mathrm{~S}$ cluster using EPR (Pu et al., 2019). We suspected that DndC is a radical SAM enzyme because the $4 \mathrm{Fe}-4 \mathrm{~S}$ cluster is coordinated by three rather than four cysteine residues (Fig. S1). We varied the SAM concentration in the PT reaction. Fig. 2A shows hundred-fold increases in PT yield with increases in the SAM concentration from $0.5 \mathrm{mM}$ to $2 \mathrm{mM}$, as indicated by the dGsA signal. We then used the cysteine mutants of DndC to analyze its involvement in DNA PT modification. Fig. 2B and Fig. S3 show that cysteine residue 39 is not required for PT. Cysteine residues 146, 280, and 283, which are responsible for the ligation of the [4Fe-4S] cluster, are essential for PT. Cysteine residues 262 and 273 are also required for PT. To further confirm a radical SAM enzyme being involved in the PT modification, reaction products were analyzed using HPLC-MS. Fig. 2C shows that in contrast to the reaction products from DndCDE purified oxically, the canonical 5'-dA mass signal was successfully detected from reaction using the anoxic DndCDE-FeS. These observations suggest that PT is a radical SAM-type reaction. Nevertheless, the detection of the dGsT signal failed, even with $2 \mathrm{mM} \mathrm{SAM}$ in the reaction mixture (not shown).

\section{R217 in DndD is involved in DNA complexation by DndCDE}

We briefly investigated the effect of ds DNA substrate length (6 bp to $50 \mathrm{bp}$, DNA3/4/5/8/12 in Table 1 respectively) on PT by DndCDE-FeS using a combination of three different approaches: 
HPLC-MS to detect the PT reaction products; CD spectroscopy to analyze conformational changes in DndCDE upon binding to DNA substrates; and electrophoresis mobility shift assays (EMSAs) to determine the avidity of DNA binding by the protein complex. The results from the HPLC-MS experiment indicated that the minimum ds DNA substrate length required for DndCDE-FeS to cause PT was $8 \mathrm{bp}$ and that PT yield increased with increasing substrate DNA length up to $24 \mathrm{bp}$ (Fig. 3A). CD spectroscopy showed that an increase of $6.8 \%$ in $\alpha$-helix content was detected for a ds DNA substrate length of $8 \mathrm{bp}$. The $\alpha$-helix content increased with increasing DNA length (Fig. 3B), suggesting that the conformation of DndCDE changed upon DNA binding. Fig. $3 \mathrm{C}$ shows that the DNA complexation signal was barely detectable at a length of $16 \mathrm{bp}$ (DNA5), and the signal was greater at length of $24 \mathrm{bp}$ (DNA8).

To analyze the effects of [Fe-S] on DndC DNA binding, we made an accidental double mutant in which cysteine 280 in DndC was mutated to alanine and arginine 217 in DndD was mutated to a cysteine. Fig. 3D(i) shows that mutations at cysteine residues in DndC did not affect DNA binding, while the C280A-R217C mutant abolished DNA binding of the DndCDE. The role of R217 was further confirmed by the DndD site-directed mutant R217C (Fig. 3D(ii)). The DndD R217 mutant allowed us to analyze the avidity of DNA binding by DndCDE and how it affected PT. Fig. 3D(iii) shows that genomic DNA was still PT-modified in the DndD R217 mutant, but the PT abundancy reduced to about $60 \%$.

\section{PT modification at dGT required DNA substrate with ss PT modification at dGA}

An interesting additional observation was that while in vivo, PT has most commonly been reported as a ds modification of DNA (Dyson \& Evans, 1998; Wang et al., 2011; Zhou et al., 2005), in our experiments using HPLC-MS, a mass peak corresponding to dGsT was not detected, suggesting that PT had occurred in a ss manner. Since DNA PT is believed to be a post-replicative (Dyson \& Evans, 1998) bi-stranded process, we suggest that a possible resolution to this apparent paradox could be that after DNA replication, the PT GsAAC/GsTTC modification of a single DNA strand is converted to a ds form. To test this hypothesis, we synthesized and HPLC-purified $R p$ and $S p$ configuration oligomers (Fig. S4), and made the 24 bp DNA fragments with a single PT site in the $R p$ form (GsAAC/GTTC, GAAC/GsTTC, DNA10/11 in Table 1 respectively) as substrates for the PT assay (Fig. 4A). A definite peak at $m / z 588.1272$ was detected by HPLC-MS assay, indicating that PT

This article is protected by copyright. All rights reserved 
had occurred at dGT using the GsAAC/GTTC substrate (Fig. 4A). When DNA containing GAAC/GsTTC was employed as substrate, dGsA PT was decreased compared to that observed for substrate without modification (The concentrations of dGsA or dGsT produced by substrates GAAC/GsTTC, GsAAC/GTTC and GAAC/GTTC were estimated in Table 2).

Controlled and directed DNA binding by DndCDE is very likely to be important for the delivery of the enzyme complex to the potential sites for subsequent PT modification. In parallel EMSA assay and CD spectral analysis, we found that ss PT modification at ds DNA substrate slightly increased the avidity of DndCDE to DNA (Fig. 4B). There was no obvious difference between the binding to 5'GsAAC/GTTC-3' and binding to 5'-GAAC/GsTTC-3' (Fig. 4B). Fig. S5 illustrates that there was no significant difference in the binding of DndCDE to $R p$ and $S p$ substrate DNA. The increase in the $\alpha-$ helix content of DndCDE was similar between binding to normal ds DNA and binding to DNA with PT modification at dGsT (Fig. 4C). In sharp contrast, a decrease of $7.29 \%$ in $\alpha$-helix content was detected upon binding to ds DNA with PT at dGsA. These results imply that DndCDE recognizes ds DNA with/without PT at dGsA/dGsT and adopts different conformations after binding to its target.

The above observations support the view that the DndCDE-FeS might not modify both strands of ds DNA simultaneously and that modification first occurs between $G$ and $A$, followed by modification between $\mathrm{G}$ and $\mathrm{T}$.

\section{Small molecules dramatically tweaked the conformation of DndCDE}

In the case of experiments in which the effect of small molecules on DndCDE DNA complexation was investigated, cysteine significantly enhanced the binding of DndCDE to non-PT substrates, while SAM had little effect on the binding of DndCDE to ds DNA (Fig. 5A). ATP reduced DndCDE complexation with substrate DNA8 (Fig. 5B), and at $8 \mathrm{mM}$ ATP, DNA binding was very significantly reduced. AMP and ADP were both observed to have less effect than ATP on the binding of DndCDE to the substrate (Fig. 5B). To test whether ATP hydrolysis played a role in the DNA complexation of DndCDE, an EMSA was carried out using ADP•AlF3 (a mimic of ATP that is not hydrolysable), and it was observed that, as in the case of ATP, DndCDE binding to substrate 8 was significantly lessened (Fig. 5B).

This article is protected by copyright. All rights reserved 
Conformational changes might have been induced in DndCDE by the small molecules in the DndCDE PT reaction. CD spectral analysis showed that SAM, ATP and cysteine were all responsible for inducing conformational changes in the protein, and in all cases, the percentage of protein in the $\alpha$ helix conformation decreased by approximately $30 \%$, while the $\beta$-sheet conformation content increased by between $3 \%$ and $6 \%$ (Fig. 5C).

\section{Discussion}

We found that PT by DndCDE-FeS occurs under only strictly anoxic conditions and that even mixing the anoxically prepared protein with SAM under oxic condition can abolish it. The Fe-S cluster in the $[4 \mathrm{Fe}-4 \mathrm{~S}]$ configuration being ligated by three cysteine residues and the reaction requirement for SAM suggested that DndCDE-FeS functions as a radical SAM-type enzyme. The

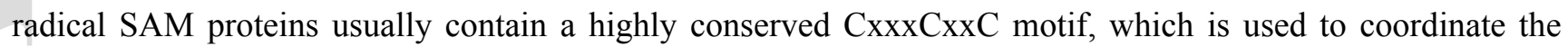
[4Fe-4S] cluster (Sofia et al., 2001). Therefore, according to this definition, DndC can be classified as a noncanonical radical SAM enzyme. Modification of nucleic acids or compounds by insertion of a sulfur is commonly found in radical SAM enzymes (Wang et al., 2014). Interestingly, our studies have illustrated that DndC shows similarity to the PAPS and APS reductase family of proteins (Zhou et al., 2005), which do not hydrolyze ATP during the reactions they catalyze (Savage et al., 1997). The requirement for SAM during PT also suggests that the nucleotide binding domain of DndC might actually bind SAM and not ATP. Common to almost all radical SAM enzymes is the formation of a 5deoxyadenosyl radical $\left(5^{\prime}-\mathrm{dA} \bullet\right)$ radical via reductive cleavage of SAM in the first step (Stich et al., 2014) of the reaction, which could then be used in the current context to 'activate' the 'inert' DNA phosphate backbone (Fig. 2C)(Fig. 6).

We postulated that the sulfur of PT bond comes directly from cysteine rather than from SAM or the $4 \mathrm{Fe}-4 \mathrm{~S}$ cluster on DndC. This is evidenced by the requirement of cysteine for the reaction to proceed (Fig. 1A)(Fig. 6). The mobilization of sulfur could be catalyzed by IscS (desulfurase), which cannot be replaced by SufS (An et al., 2012). The direct delivery of sulfur to DNA could potentially be catalyzed by the Cys262 and Cys 273 residue in DndC, because site-directed mutation of these two cysteine residues abolished the PT modification (Fig. S3). It should be noted that key biochemical intermediates are waiting to be identified and there is a considerable uncertainty to propose a solid mechanism pathway for the PT reaction. Nevertheless, we envisage a potential involvement of 
thiyl/perthiyl radicals (Schöneich, 2017) in the reaction (Fig. 6), laying the ground for further investigations.

Sulfur incorporation during PT has been suggested to require energy (Eckstein, 2007), while both DndC and DndD proteins in phosphorothioating enzymes have been shown to hydrolyze ATP (An et al., 2012; Yao et al., 2009). The findings presented here support the hypothesis that ATP is helpful but not essential for PT to occur (Fig 5B). We suggest that rather than being directly involved in PT, the ATP binding capability possessed by DndD might help to release DndCDE from substrate DNA post PT or to find conserved GAAC/GTTC modification sites. In accordance with the involvement of ATP in the PT modification process is the observation that in the presence of ATP, DndB, the repressor of the $d n d$ gene cluster, disassociates from DNA to allow the transcription of the PT modification genes (Xia et al., 2019).

PT occurs on both strands of DNA in vivo (Dyson \& Evans, 1998; Liang et al., 2007; Zhou et al., 2005), and it is a one-step process, with the substitution occurring simultaneously on both strands (Cao et al., 2015). Our work does not support that suggestion; rather, we observed that in vitro PT occurred on only one strand of ds DNA substrate. The previous observations that genomic DNA extracted from bacteria mostly bears the PT modification on both DNA strands (Dyson \& Evans, 1998; Liang et al., 2007; Wang et al., 2011; Zhou et al., 2005) does not necessarily disagree with our finding. The explanation could be that since PT has been reported to be a postreplicative (Boybek et al., 1998; Dyson \& Evans, 1998) process, PT of the newly synthesized DNA strand may rely on PT of the conserved strand for directing the phosphorothioating enzyme second-strand binding and activity. Therefore, ss PT modification would be the first step in what eventually becomes ds PT DNA in vivo. At present, this seems to be the best possible explanation for the differences between our results in vitro and those previously reported (Cao et al., 2015). This is especially the case as so far no evidence has been provided to show or suggest that anything other than the phosphorothioating enzyme is involved in the simultaneous PT of both strands of ds DNA. A possible advantage of ss PT might be the avoidance of DNA degradation during the modification itself. Modification of one strand at a time would avoid the generation of two radical species simultaneously, which could increase the chance of DNA ds breakage. The preferential binding of DndCDE to ss PT oligonucleotides (Fig. 4B) reported in this study and the requirement of first-strand PT modification before second-strand PT (Fig. 4A), 
revealed in our studies, support this notion. In summary, with the results we have obtained and the hypothesis we have advanced, we have provided a possible description of the PT activity of DndCDEFeS.

\section{Experimental Procedures}

Bacterial strains, plasmids, culture conditions, protein expression and purification.

The compounds 5'-dA, cysteine, S-adenosyl-L-methionine (SAM), ATP and DTT were purchased from Sigma-Aldrich (Merck KGaA, Darmstadt, Germany). Synthetic dinucleotide dG $\mathrm{d}_{\mathrm{S}}$ and $\mathrm{dG}_{\mathrm{S}} \mathrm{T}$ standards were purchased from GENEWIZ (Jiangsu, China). The bacterial strains and plasmids used in this work, except for the DndD mutant R217C, have been described in previous publications ( $\mathrm{Pu}$ et al., 2019; Xiong et al., 2015). The primers used to generate the DndD mutant R217C were 5'- TTATCAAATGCCAGCAAACTGCCCAGTTGGGTGGCTC-3' and 5'GTTTGCTGGCATTTGATAAAAATCATCAGATCATTTT-3'. The mutation protocol had been described by $\mathrm{Pu}$ et al (Pu et al., 2019). Bacterial cell culture conditions, protein expression, and purification of His-tagged cysteine desulfurase (IscS) and DndCDE were also described in detail in a previous publication. In vitro anoxic enzymatic formation of the Fe-S cluster in DndCDE (DndCDE$\mathrm{FeS}$ ), and electrophoresis mobility shift assays (EMSAs) used previously established protocols without modification (Pu et al., 2019).

In vitro measurement of PT activity under anoxic and oxic conditions. Experiments reported in this work relating to the detection of DNA PT by DndCDE-FeS were designed and carried out to elucidate the factors important in mediating and contributing to the process and investigated the effects of cofactors on the reaction and why only one strand of DNA is phosphorothioated in vitro. DndCDE was never observed to possess PT activity.

For the preparation of substrate DNA, short, double-stranded substrate DNA fragments of 6, 8, 16, 24 and $50 \mathrm{bp}$ (DNA3/4/5/8/12) in length were used as a basis for measuring PT and were synthesized by and obtained from GENEWIZ (Jiangsu, China) as sense and antisense oligonucleotides (Table 1). Substrate DNA solutions used in PT assay reactions were prepared as 500 $\mu \mathrm{L}$ volumes containing $50 \mu \mathrm{L}$ of $400 \mu \mathrm{M}$ sense and antisense oligonucleotide, $100 \mu \mathrm{L}$ of $5 \times$ annealing buffer $\left(150 \mathrm{mM}\right.$ Tris $\cdot \mathrm{HCl}, \mathrm{pH} 8.0,50 \mathrm{mM} \mathrm{MgCl}_{2}$, and $\left.240 \mathrm{mM} \mathrm{NaCl}\right)$ and $300 \mu \mathrm{L}$ of water. 
Prior to use in PT assay reactions, these mixtures were heated to $100{ }^{\circ} \mathrm{C}$ for $10 \mathrm{~min}$ and then slowly cooled to room temperature to remove any misannealing that may have occurred in the case of ds DNA substrates. The substrate DNA solutions were then either used immediately in PT reactions or stored frozen until required. In the case of anoxic DNA PT assays, the whole procedure was performed in an anoxic glove box.

PT assay reactions were performed in three steps. The first step was DNA binding by DndCDE. A $1.2 \mathrm{~mL}$ (total volume) solution contained $750 \mu \mathrm{L}$ of DndCDE $(20 \mu \mathrm{M}), 75 \mu \mathrm{L}$ of IscS $(200 \mu \mathrm{M})$ in storage buffer (see previous) and $375 \mu \mathrm{L}$ of substrate DNA (DNA12). The solution was dialyzed for 3 $\mathrm{h}$ in $1 \mathrm{~L}$ of Bis-Tris buffer (50 mM Bis-Tris $\mathrm{pH} 6.5,150 \mathrm{mM} \mathrm{NaCl}$, and $5 \%$ glycerol) previously degassed in an anoxic glove box for 2 days. The decrease in $\mathrm{pH}$ to 6.5 increased the effectiveness of DNA binding by the complex. The second step was the formation of an iron-sulfur cluster and hence the 'active' DndCDE-FeS on DNA. DTT, $\mathrm{Fe}\left(\mathrm{NH}_{4}\right)_{2}\left(\mathrm{SO}_{4}\right)_{2}$ and cysteine were added to the mixture at final concentrations of $7.5 \mathrm{mM}, 0.5 \mathrm{mM}$, and $0.5 \mathrm{mM}$, respectively, which was then incubated anoxically at $4{ }^{\circ} \mathrm{C}$ overnight. The mixture was then dialyzed for $3 \mathrm{~h}$ at $4{ }^{\circ} \mathrm{C}$ in $1 \mathrm{~L}$ of Bis-Tris buffer to remove the DTT, cysteine and $\mathrm{Fe}\left(\mathrm{NH}_{4}\right)_{2}\left(\mathrm{SO}_{4}\right)_{2}$. The dialysis step can be performed for a longer time or overnight which is not harmful to the PT reaction. Removing the small molecules using a desalt column also works. The third step was the initiation of the PT reaction. The mixture was divided into $100 \mu \mathrm{L}$ aliquots in sterile microcentrifuge tubes and ATP $(1 \mathrm{mM}), \mathrm{Mg}^{2+}(1 \mathrm{mM})$, cysteine $(1 \mathrm{mM})$, and/or SAM (1.5 mM) were added to initiate PT which was allowed to proceed for 2 to $3 \mathrm{~h}$ at room temperature under anoxic conditions in a glove box. Finally, the reaction mixtures were boiled for 10 min, rapidly chilled on ice and centrifuged at $15000 \mathrm{~g}$ for $10 \mathrm{~min}$ at room temperature to remove protein precipitate.

For the detection of the PT reaction product, the supernatant was carefully removed and added to $400 \mu \mathrm{L}$ of sterile double-distilled water, and the entire $500 \mu \mathrm{L}$ was loaded into sterile, dialysis tubing (Sangon Biotech) that was suspended in $1 \mathrm{~L}$ of sterile double-distilled water and allowed to dialyze overnight. At the end of that time, the sample volume had increased to approximately $1 \mathrm{~mL}$. The dialyzed sample was then lyophilized in a FreeZone 12 Liter Console Freeze Dryer (LABCONCO, Missouri, USA) under vacuum at $-70{ }^{\circ} \mathrm{C}$, and the resulting DNA was resuspended in $100 \mu \mathrm{L}$ of $90 \%$ $\mathrm{v} / \mathrm{v}$ aqueous methyl alcohol and centrifuged at $15000 \mathrm{~g}$ for $20 \mathrm{~min}$ to remove salt. The supernatant

This article is protected by copyright. All rights reserved 
was collected and dried in a rotary evaporator (CHRIST RVC 2-25 CD plus, CHRIST, Osterode, Germany) under vacuum at $37^{\circ} \mathrm{C}$. Finally, the resultant DNA pellet was resuspended in $60 \mu \mathrm{L}$ of sterile double distilled water, and digested with P1 and FastAP nuclease and analyzed for PT using HPLC-MS as described previously.

\section{Protein secondary structure determination by circular dichroism (CD) spectroscopy.}

One milliliter of purified DndCDE (equivalent to 10 nmoles of protein) in storage buffer (20 mM Tris $\cdot \mathrm{HCl}, \mathrm{pH} 8.0,150 \mathrm{mM} \mathrm{NaCl}, 5 \%$ glycerol) was dialyzed in $1 \mathrm{~L}$ of CD buffer $(20 \mathrm{mM}$ $\mathrm{Na}_{2} \mathrm{HPO}_{4} \cdot \mathrm{NaH}_{2} \mathrm{PO}_{4} \mathrm{pH} 7.0,150 \mathrm{mM} \mathrm{NaF}$, and $5 \%$ glycerol) for $6 \mathrm{~h}$ at $4{ }^{\circ} \mathrm{C}$. Subsequently, the protein concentration was adjusted to $0.42 \mu \mathrm{M}$ with $\mathrm{CD}$ detection buffer, and $400 \mu \mathrm{L}$ of the solution used in CD spectroscopy experiments. This amount of protein was employed, as at higher concentrations, photomultiplier tube outputs exceeded $500 \mathrm{~V}$.

To assess the effects of small molecules and DNA (listed in Fig. 4 and Fig. 5) on the conformation of DndCDE, ATP, cysteine, S-adenosyl methionine and/or substrate DNA (DNA12) were added to the DndCDE solution to final concentrations of $0.5 \mathrm{mM}, 1 \mathrm{mM}, 1.5 \mathrm{mM}$ and $0.42 \mu \mathrm{M}$, respectively. The mixtures were incubated for $5 \mathrm{~min}$ at $25^{\circ} \mathrm{C}$ (in the case of small molecules) prior to CD analysis, and those composed of the DndCDE and substrate DNA were incubated for 20 min at room temperature. All CD analysis was performed with a Jasco J-815 circular dichroism (CD) spectropolarimeter (Jasco, Oklahoma, USA) set to 'standard sensitivity' using a $1 \mathrm{~mm}$ cell length and a wavelength scan range of 190 to $260 \mathrm{~nm}$ at a scan speed of $50 \mathrm{~nm} / \mathrm{min}$. All data generated were analyzed using K2D3 software (developed in the Sprott Center for Stem Cell Researchearch, Ottawa Hospital Research Institute, Ottawa, Canada) (Louis-Jeune et al., 2012) to permit calculation of protein $\alpha$-helix and $\beta$-strand content.

\section{Agarose gel electrophoresis detection of PT DNA.}

DNA phosphorothioation of assay DNA was initially confirmed by TAE agarose gel electrophoresis following the protocol of An et al (An et al., 2012). Briefly, $4 \mu \mathrm{g}$ of (phosphorothioated) DNA in $8 \mu \mathrm{L}$ of sterile double-distilled $\mathrm{H}_{2} \mathrm{O}$ was mixed with $1 \mu \mathrm{L}$ of $10 \times \mathrm{TAE}$ buffer (400 mM Tris, $200 \mathrm{mM}$ sodium acetate, $8 \mathrm{mM}$ EDTA pH 7.5) and left to rest for $5 \mathrm{~min}$ at 25

${ }^{\circ} \mathrm{C}$ after which Tris-peracetic acid (TPA) was added to a final concentration of $10 \mathrm{mM}$ (from a 100 
$\mathrm{mM}$ stock) and the mixture was incubated at $37{ }^{\circ} \mathrm{C}$ for $30 \mathrm{~min}$. The samples were then subjected to $1 \%$ agarose gel electrophoresis in the presence of $50 \mathrm{mM}$ thiourea to inhibit any further TPA activity (Xie et al., 2012). The presence of a smear on gels indicated phosphorothioate DNA.

\section{HPLC/MS detection of PT DNA.}

The HPLC-MS standard assay employed in PT DNA analysis in this study was set-up using phosphorothioated genomic DNA isolated from the IPTG-induced E. coli strain BL21(DE3)/plysS possessing pDndBCDE $\mathrm{H}_{\mathrm{H}}$ using a Dzup Genomic DNA Isolation Reagent kit (Sangon Biotech, Shanghai, China) and was based upon the procedure reported by Wang et al (Wang et al., 2011; Wang et al., 2007).

Briefly, $50 \mu \mathrm{g}$ of phosphorothioated DNA in $89 \mu \mathrm{L}$ of water was digested with 1 unit of P1 nuclease (Sigma, Shanghai China) at $50{ }^{\circ} \mathrm{C}$ in $1 \times$ nuclease P1 buffer ( $30 \mathrm{mM} \mathrm{NaAc} \mathrm{pH} 5.3,5 \mathrm{mM}$ $\mathrm{ZnCl}_{2}, 50 \mathrm{mM} \mathrm{NaCl}$ ) for $4 \mathrm{~h}$ in a sterile microcentrifuge tube. Subsequently, 1 unit of FastAP (Thermo Fisher Scientific Inc., Massachusetts, USA) and $1 \times$ FAST AP buffer were added to the mixture, which was incubated for an additional $4 \mathrm{~h}$ at $37{ }^{\circ} \mathrm{C}$. The reaction was then terminated by boiling for $10 \mathrm{~min}$ and centrifuged at $18000 \mathrm{~g}$ at $4{ }^{\circ} \mathrm{C}$ for $20 \mathrm{~min}$ to remove denatured protein. The reaction supernatant was loaded into an $\operatorname{Amicon}^{\circledR}$ Ultra $0.5 \mathrm{~mL}$ centrifugal filter (Merck) and centrifuged at $8000 \mathrm{~g}$ for $2 \mathrm{~h}$ at $4{ }^{\circ} \mathrm{C}$. The eluate was collected, and $20 \mu \mathrm{L}$ was loaded onto an AgilentC18 reverse-phase column $(250 \mathrm{~mm} \times 4.6 \mathrm{~mm}, 5 \mu \mathrm{m}$ Agilent Technologies $)$ fitted to an Agilent 1290MS 6230 HPLC. Sample separation was achieved by using a two-solvent mixture (A: $0.1 \%$ acetic acid in water and B: $0.1 \%$ acetic acid in acetonitrile) at a flow rate of $0.4 \mathrm{~mL} / \mathrm{min}$ and a temperature of $30{ }^{\circ} \mathrm{C}$. Gradient conditions were $1 \%$ to $13 \%$ solvent B for $10 \mathrm{~min}, 13 \%$ to $30 \%$ solvent B for 20 min and finally $1 \%$ solvent $\mathrm{B}$ for $10 \mathrm{~min}$. The ionization was set to positive mode, gas flow was 10 $\mathrm{L} / \mathrm{min}$, nebulizer pressure to $30 \mathrm{psi}$, drying gas temperature to $325^{\circ} \mathrm{C}$ and capillary voltage to $3100 \mathrm{~V}$. Dinucleotide dGsA was monitored at $\mathrm{m} / \mathrm{z}$ 597.1388, while dGsT was monitored at $\mathrm{m} / \mathrm{z}$ 588.1272. Synthetic control oligonucleotides (24 bp-ds-GsA/GsT, DNA9 in Table 1) were purchased from GENEWIZ, Jiangsu, China.

Quantification of PT abundance was performed as follows. To make a standard curve for the nucleotides, $10 \mu \mathrm{L} 5,12.5,25,50,100 \mu \mathrm{M}$ of dGsA or dGsT were detected with HPLC/MS 
respectively. The linear relationships between the nucleotide peak area and the concentrations of the dinucleotides were then obtained. To calculate the PT reaction production, $10 \mu \mathrm{L}$ of the nuclease digestion product was analyzed using HPLC/MS. Peak areas of dGsA and dGsT were obtained. The yields of the dGsA and dGsT products were then calculated using the standard curve.

\section{Analysis of 5'-dA in the enzymatic product of PT assay reactions.}

In contrast to the detection of PT dinucleotides in PT assay reactions, reaction mixtures $(100 \mu \mathrm{L})$ were treated with $900 \mu \mathrm{L}$ of methanol to inactivate and precipitate the protein after 2-3 h of incubation in the glove box. The mixtures were centrifuged at $15000 \mathrm{~g}$ for $10 \mathrm{~min}$ at room temperature to remove protein precipitate. The supernatants were then collected and dried in a rotary evaporator (CHRIST RVC 2-25 CD plus, CHRIST, Osterode, Germany) under vacuum at $30{ }^{\circ} \mathrm{C}$. The resultant pellet was resuspended in $40 \mu \mathrm{L}$ of sterile double distilled water.

LC-HRMS (liquid chromatogram - high resolution mass spectrum) analysis of 5'-dAo was performed on an Agilent 1200 series coupled with a 6530 Accurate-Mass Q-TOF mass spectrometer in positive mode using a reversed-phase column (Agilent, $250 \times 4.6 \mathrm{mM}, 5 \mu \mathrm{M}$ ) based on the method described by Jin et al (Jin et al., 2018). The mobile phase comprised solvent A $(0.1 \%$ formic acid in Milli-Q water) and solvent B (0.1\% formic acid in acetonitrile). The gradient was as follows: $5 \%$ B $(0-5 \mathrm{~min}) ; 5 \% \mathrm{~B}$ to $20 \% \mathrm{~B}(5-20 \mathrm{~min}) ; 20 \%$ to $90 \% \mathrm{~B}(20-24 \mathrm{~min}) ; 90 \% \mathrm{~B}(24-27 \mathrm{~min}) ; 90 \% \mathrm{~B}$ to $5 \% \mathrm{~B}(27-29 \mathrm{~min})$ and $5 \% \mathrm{~B}(29-35 \mathrm{~min})$. The flow rate was $0.3 \mathrm{~mL} / \mathrm{min}$, and the detection wavelength was $254 \mathrm{~nm}$. The gas flow was $8 \mathrm{~L} / \mathrm{min}$, the nebulizer pressure was 35 psi, and the drying gas temperature was $300^{\circ} \mathrm{C}$. The presence of 5' -dA was monitored at $\mathrm{m} / \mathrm{z} 252.1097$.

\section{Acknowledgements}

We thank Prof. Gong-Li Tang for his generous support for providing anoxic box for the study. We thank Dr. Yuanhua and Jin Wenbing from Prof. Tang Gong-Li's group for their guidance in performing the anoxic protein purification, Tong Wei, Yu Lu and Zou Youming (National High Magnetic Field Laboratory of the Chinese Academy of Sciences, Hefei, China) for EPR operation and data collection, and also thank the core facility of School of Life Science and Biotechnology for the help of Q-Tof. This work was supported by the National Key Research and Development Program of

This article is protected by copyright. All rights reserved 
China (2018YFA0900702), the National Science Foundation of China (31470830, 21661140002, 91753123), and the Ministry of Science and Technology (973 program, 2015CB554203).

\section{Author contributions}

(i) the conception or design of the study: ZJW, JDL, ZXD, TNP.

(ii) the acquisition, analysis, or interpretation of the data: TNP, ZLM, WZ.

(iii) writing of the manuscript: TNP, ZJW, JDL, LWJ, XFZ.

This article is protected by copyright. All rights reserved 


\section{References}

Alonso, R., Martin, A., Pelaez, T., Marin, M., Rodriguez-Creixems, M., \& Bouza, E. (2005). An improved protocol for pulsed-field gel electrophoresis typing of Clostridium difficile. $J$ Med Microbiol, 54(Pt 2), 155-157. doi:10.1099/jmm.0.45808-0

An, X., Xiong, W., Yang, Y., Li, F., Zhou, X., Wang, Z., et al. (2012). A novel target of IscS in Escherichia coli: participating in DNA phosphorothioation. PLoS One, 7(12), e51265. doi:10.1371/journal.pone.0051265

Boybek, A., Ray, T. D., Evans, M. C., \& Dyson, P. J. (1998). Novel site-specific DNA modification in Streptomyces: analysis of preferred intragenic modification sites present in a $5.7 \mathrm{~kb}$ amplified DNA sequence. Nucleic Acids Res, 26(14), 3364-3371.

Cao, B., Chen, C., DeMott, M. S., Cheng, Q., Clark, T. A., Xiong, X., et al. (2014). Genomic mapping of phosphorothioates reveals partial modification of short consensus sequences. Nat Commun, 5, 3951. doi:10.1038/ncomms4951

Cao, B., Zheng, X., Cheng, Q., Yao, F., Zheng, T., Ramesh Babu, I., et al. (2015). In vitro analysis of phosphorothioate modification of DNA reveals substrate recognition by a multiprotein complex. Sci Rep, 5, 12513. doi:10.1038/srep12513

Chen, C., Wang, L., Chen, S., Wu, X., Gu, M., Chen, X., et al. (2017). Convergence of DNA methylation and phosphorothioation epigenetics in bacterial genomes. Proc Natl Acad Sci U S A, 114(17), 4501-4506. doi:10.1073/pnas. 1702450114

Dyson, P., \& Evans, M. (1998). Novel post-replicative DNA modification in Streptomyces: analysis of the preferred modification site of plasmid pIJ101. Nucleic Acids Res, 26(5), 1248-1253.

Eckstein, F. (2007). Phosphorothioation of DNA in bacteria. Nat Chem Biol, 3(11), 689-690. doi:10.1038/nchembio1107-689

Holliday, G. L., Akiva, E., Meng, E. C., Brown, S. D., Calhoun, S., Pieper, U., et al. (2018). Atlas of the Radical SAM Superfamily: Divergent Evolution of Function Using a "Plug and Play" Domain. Methods Enzymol, 606, 1-71. doi:10.1016/bs.mie.2018.06.004

Hu, W., Wang, C., Liang, J., Zhang, T., Hu, Z., Wang, Z., et al. (2012). Structural insights into DndE from Escherichia coli B7A involved in DNA phosphorothioation modification. Cell Res, 22(7), 1203-1206. doi:10.1038/cr.2012.66

This article is protected by copyright. All rights reserved 
Jin, W. B., Wu, S., Jian, X. H., Yuan, H., \& Tang, G. L. (2018). A radical S-adenosyl-L-methionine enzyme and a methyltransferase catalyze cyclopropane formation in natural product biosynthesis. Nat Commun, 9(1), 2771. doi:10.1038/s41467-018-05217-1

Kellner, S., DeMott, M. S., Cheng, C. P., Russell, B. S., Cao, B., You, D., et al. (2017). Oxidation of phosphorothioate DNA modifications leads to lethal genomic instability. Nat Chem Biol, 13(8), 888-894. doi:10.1038/nchembio.2407

Lanz, N. D., \& Booker, S. J. (2015). Auxiliary iron-sulfur cofactors in radical SAM enzymes. Biochim Biophys Acta, 1853(6), 1316-1334. doi:10.1016/j.bbamcr.2015.01.002

Liang, J., Wang, Z., He, X., Li, J., Zhou, X., \& Deng, Z. (2007). DNA modification by sulfur: analysis of the sequence recognition specificity surrounding the modification sites. Nucleic Acids Res, 35(9), 2944-2954. doi:10.1093/nar/gkm176

Louis-Jeune, C., Andrade-Navarro, M. A., \& Perez-Iratxeta, C. (2012). Prediction of protein secondary structure from circular dichroism using theoretically derived spectra. Proteins, 80(2), 374-381. doi:10.1002/prot.23188

Mulliez, E., Duarte, V., Arragain, S., Fontecave, M., \& Atta, M. (2017). On the Role of Additional [4Fe-4S] Clusters with a Free Coordination Site in Radical-SAM Enzymes. Front Chem, 5, 17. doi:10.3389/fchem. 2017.00017

Pu, T., Liang, J., Mei, Z., Yang, Y., Wang, J., Zhang, W., et al. (2019). Phosphorothioated DNA Is Shielded from Oxidative Damage. Appl Environ Microbiol, 85(8). doi:10.1128/aem.00104-19

Ray, T., Mills, A., \& Dyson, P. (1995). Tris-dependent oxidative DNA strand scission during electrophoresis. Electrophoresis, 16(6), 888-894.

Savage, H., Montoya, G., Svensson, C., Schwenn, J. D., \& Sinning, I. (1997). Crystal structure of phosphoadenylyl sulphate (PAPS) reductase: a new family of adenine nucleotide alpha hydrolases. Structure, 5(7), 895-906.

Schöneich, C. (2017). Sulfur Radical-Induced Redox Modifications in Proteins: Analysis and Mechanistic Aspects. Antioxidants \& Redox Signaling, 26(8), 388-405. doi:10.1089/ars.2016.6779

Sofia, H. J., Chen, G., Hetzler, B. G., Reyes-Spindola, J. F., \& Miller, N. E. (2001). Radical SAM, a novel protein superfamily linking unresolved steps in familiar biosynthetic pathways with 
radical mechanisms: functional characterization using new analysis and information visualization methods. Nucleic Acids Research, 29(5), 1097-1106. doi:10.1093/nar/29.5.1097

Stich, T. A., Myers, W. K., \& Britt, R. D. (2014). Paramagnetic intermediates generated by radical Sadenosylmethionine (SAM) enzymes. Acc Chem Res, 47(8), 2235-2243. doi:10.1021/ar400235n

Tong, T., Chen, S., Wang, L., Tang, Y., Ryu, J. Y., Jiang, S., et al. (2018). Occurrence, evolution, and functions of DNA phosphorothioate epigenetics in bacteria. Proc Natl Acad Sci USA, 115(13), E2988-e2996. doi:10.1073/pnas.1721916115

Wang, J., Woldring, R. P., Roman-Melendez, G. D., McClain, A. M., Alzua, B. R., \& Marsh, E. N. (2014). Recent advances in radical SAM enzymology: new structures and mechanisms. $A C S$ Chem Biol, 9(9), 1929-1938. doi:10.1021/cb5004674

Wang, L., Chen, S., Vergin, K. L., Giovannoni, S. J., Chan, S. W., DeMott, M. S., et al. (2011). DNA phosphorothioation is widespread and quantized in bacterial genomes. Proc Natl Acad Sci US A, 108(7), 2963-2968. doi:10.1073/pnas.1017261108

Wang, L., Chen, S., Xu, T., Taghizadeh, K., Wishnok, J. S., Zhou, X., et al. (2007). Phosphorothioation of DNA in bacteria by dnd genes. Nat Chem Biol, 3(11), 709-710. doi:10.1038/nchembio.2007.39

Wang, L., Jiang, S., Deng, Z., Dedon, P. C., \& Chen, S. (2018). DNA phosphorothioate modification - a new multi-functional epigenetic system in bacteria. FEMS Microbiology Reviews, 43(2), 109-122. doi:10.1093/femsre/fuy036

Wu, T., Huang, Q., Wang, X. L., Shi, T., Bai, L., Liang, J., et al. (2017). Mechanistic Investigation on ROS Resistance of Phosphorothioated DNA. Sci Rep, 7, 42823. doi:10.1038/srep42823

Xia, S., Chen, J., Liu, L., Wei, Y., Deng, Z., Wang, L., et al. (2019). Tight control of genomic phosphorothioate modification by the ATP-modulated autoregulation and reusability of DndB. Mol Microbiol, 111(4), 938-950. doi:10.1111/mmi.14186

Xie, X., Liang, J., Pu, T., Xu, F., Yao, F., Yang, Y., et al. (2012). Phosphorothioate DNA as an antioxidant in bacteria. Nucleic Acids Res, 40(18), 9115-9124. doi:10.1093/nar/gks650

Xiong, L., Liu, S., Chen, S., Xiao, Y., Zhu, B., Gao, Y., et al. (2019). A new type of DNA phosphorothioation-based antiviral system in archaea. Nat Commun, 10(1), 1688. 
doi:10.1038/s41467-019-09390-9

Xiong, W., Zhao, G., Yu, H., \& He, X. (2015). Interactions of Dnd proteins involved in bacterial DNA phosphorothioate modification. Front Microbiol, 6, 1139. doi:10.3389/fmicb.2015.01139

Xu, T., Yao, F., Zhou, X., Deng, Z., \& You, D. (2010). A novel host-specific restriction system associated with DNA backbone S-modification in Salmonella. Nucleic Acids Res, 38(20), 7133-7141. doi:10.1093/nar/gkq610

Yang, Y., Xu, G., Liang, J., He, Y., Xiong, L., Li, H., et al. (2017). DNA Backbone SulfurModification Expands Microbial Growth Range under Multiple Stresses by its anti-oxidation function. Sci Rep, 7(1), 3516. doi:10.1038/s41598-017-02445-1

Yao, F., Xu, T., Zhou, X., Deng, Z., \& You, D. (2009). Functional analysis of spfD gene involved in DNA phosphorothioation in Pseudomonas fluorescens Pf0-1. FEBS Lett, 583(4), 729-733. doi:10.1016/j.febslet.2009.01.029

You, D., Wang, L., Yao, F., Zhou, X., \& Deng, Z. (2007). A novel DNA modification by sulfur: DndA is a NifS-like cysteine desulfurase capable of assembling DndC as an iron-sulfur cluster protein in Streptomyces lividans. Biochemistry, 46(20), 6126-6133. doi:10.1021/bi602615k

Zhou, X., Deng, Z., Firmin, J. L., Hopwood, D. A., \& Kieser, T. (1988). Site-specific degradation of Streptomyces lividans DNA during electrophoresis in buffers contaminated with ferrous iron. Nucleic Acids Res, 16(10), 4341-4352.

Zhou, X., He, X., Liang, J., Li, A., Xu, T., Kieser, T., et al. (2005). A novel DNA modification by sulphur. Mol Microbiol, 57(5), 1428-1438. doi:10.1111/j.1365-2958.2005.04764.x

This article is protected by copyright. All rights reserved 
Table 1. DNA fragments.

\begin{tabular}{|c|c|c|c|}
\hline \multicolumn{2}{|l|}{ DNA } & Sequence $\left(5^{\prime} \rightarrow 3^{\prime}\right)$ & $\begin{array}{l}\text { Source/ } \\
\text { Reference }\end{array}$ \\
\hline 24 nt-ss-GsA* & & CCTCTTGCGGGsAACTCTCGCTTTG & \multirow{12}{*}{$\begin{array}{l}\text { This } \\
\text { study }\end{array}$} \\
\hline 24 nt-ss-GsT & & CAAAGCGAGAGsTTCCCGCAAGAGG & \\
\hline \multirow{2}{*}{6 bp-ds-GA/GT } & sense & GGAACT & \\
\hline & antisense & AGTTCC & \\
\hline \multirow{2}{*}{8 bp-ds-GA/GT } & sense & GGGAACTC & \\
\hline & antisense & GAGTTCCC & \\
\hline \multirow{2}{*}{16 bp-ds-GA/GT } & sense & TTGCGGGAACTCTCGC & \\
\hline & antisense & GCGAGAGTTCCCGCAA & \\
\hline \multirow{2}{*}{18 bp-ds-GA/GT } & sense & CTTGCGGGAACTCTCGCT & \\
\hline & antisense & AGCGAGAGTTCCCGCAAG & \\
\hline \multirow{2}{*}{20 bp-ds-GA/GT } & sense & TCTTGCGGGAACTCTCGCTT & \\
\hline & antisense & AAGCGAGAGTTCCCGCAAGA & \\
\hline $24 \mathrm{hn} d \mathrm{CA} \wedge \mathrm{CT}$ & sense & CCTCTTGCGGGAACTCTCGCTTTG & \multirow{2}{*}{$\begin{array}{l}(\mathrm{Pu} \text { et al., } \\
2019)\end{array}$} \\
\hline 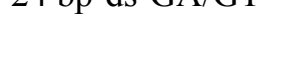 & antisense & CAAAGCGAGAGTTCCCGCAAGAGG & \\
\hline \multirow{2}{*}{$24 \mathrm{bp}-\mathrm{ds}-\mathrm{GsA} / \mathrm{GsT}$} & sense & CCTCTTGCGGGsAACTCTCGCTTTG & \multirow{10}{*}{$\begin{array}{l}\text { This } \\
\text { study }\end{array}$} \\
\hline & antisense & CAAAGCGAGAGsTTCCCGCAAGAGG & \\
\hline \multirow{2}{*}{24 bp-ds-GsA/GT } & sense & CCTCTTGCGGGsAACTCTCGCTTTG & \\
\hline & antisense & CAAAGCGAGAGTTCCCGCAAGAGG & \\
\hline \multirow{2}{*}{24 bp-ds-GA/GsT } & sense & CCTCTTGCGGGAACTCTCGCTTTG & \\
\hline & antisense & CAAAGCGAGAGsTTCCCGCAAGAGG & \\
\hline \multirow{4}{*}{ 50bp-ds-GA/GT } & \multirow{2}{*}{ sense } & GAAAGTACCCCCTCTTGCGGGAACTCTCGCTTTG & \\
\hline & & GCTGCTGGACCTGTAC & \\
\hline & \multirow{2}{*}{ antisense } & GTACAGGTCCAGCAGCCAAAGCGAGAGTTCCCGC & \\
\hline & & AAGAGGGGGTACTTTC & \\
\hline
\end{tabular}

* s: phosphorothioation at site

This article is protected by copyright. All rights reserved 
Table 2 Concentration of product (GsA or GsT)

\begin{tabular}{ccc}
\hline Substrate & Product & Concentration $(\boldsymbol{\mu M})$ \\
\hline GoA/GsT & GsA & 0.2 \\
GoA/GoT & & 3.7 \\
\hline GsA/GoT & \multirow{2}{*}{ GsT } & 0.1 \\
GoA/GoT & & NA \\
\hline
\end{tabular}




\section{Figure Legends}

Fig 1. The phosphorothioate reaction catalyzed by DndCDE-FeS.

The reaction mixture contained $1.5 \mathrm{mM}$ SAM, $1 \mathrm{mM} \mathrm{Mg}{ }^{2+}, 1 \mathrm{mM} \mathrm{ATP}, 1 \mathrm{mM}$ cysteine, and $20 \mu \mathrm{M}$ DndCDE-FeS or DndCDE plus $20 \mu \mathrm{M}$ IscS and $0.4 \mu \mathrm{M}$ substrate DNA. After PT reaction, DNA was digested using nucleases by established protocols (Wang et al., 2011; Wang et al., 2007), as described in the Methods section. Successful PT reactions should yield the deoxynucleotide dGsA or dGsT, which have a calculated $\mathrm{m} / \mathrm{z}$ of 597.1393 and 588.1272 , respectively. The reaction products were detected using HPLC/MS for deoxynucleotide (i) dGsA or (ii) dGsT.

(A) Effects of small molecules on the PT reaction. The small molecules were omitted from the reaction mixture one by one.

(B) The involvement of the iron-sulfur cluster in the PT reaction. The Dnd protein complex used in the reaction was anoxically reconstituted (dark green, resulting in a [4Fe-4S] cluster) (Pu et al., 2019), oxically purified (brown, [3Fe-4S]), or treated using $1 \mathrm{mM} \alpha, \alpha$ '-dipyridyl (gray), which removed the Fe-S cluster.

Fig 2. The radical SAM enzyme of DndCDE-FeS.

(A) HPLC traces showing the effect of SAM concentration on the PT reaction yield.

An increasing amount of SAM was used in the PT reaction. The reaction product deoxynucleotide dGsA was detected using HPLC/MS. The quantities of dGsA were estimated from the HPLC peak areas.

(B) Analysis of genomic DNA PT modification in DndC mutants.

Genomic DNA was extracted from E. coli DH10B strains harboring the dnd gene cluster with a dndC mutation. Each of the six cysteine residues in DndC was mutated to an alanine residue. The genomic DNA was cleaved using peracetic acid (PAA) (An et al., 2012; Xie et al., 2012). The DNA samples were subjected to agarose gel electrophoresis. The smear pattern of the DNA band indicates PT modification. DNA with PT modification is marked with orange color.

(C) The SAM cleavage reaction.

This article is protected by copyright. All rights reserved 
The reaction mixture contained $1.5 \mathrm{mM}$ SAM, $1 \mathrm{mM} \mathrm{Mg}^{2+}, 1 \mathrm{mM}$ ATP, $1 \mathrm{mM}$ cysteine, and $20 \mu \mathrm{M}$ DndCDE-FeS (dark green) or DndCDE (brown) plus $20 \mu \mathrm{M}$ IscS and $0.4 \mu \mathrm{M}$ DNA. The reaction products were analyzed using HPLC/MS. In radical SAM reactions, reductive cleavage of SAM gives rise to 5'-deoxyadenosine (5'-dA), which has a calculated $m / z$ of 252.1097.

Fig 3. DNA chain length requirement for PT reaction

(A) HPLC traces showing DNA substrates with increasing chain length and the yield of dGsA from PT.

(B) Circular dichroism spectra of DndCDE protein upon binding to DNA substrate. The content of $\alpha$ helices and $\beta$-strands were analyzed using K2D3 software.

(C) EMSA analysis of DndCDE binding to DNA of increasing chain length.

(D) Mutational analysis of DNA binding by DndCDE and the related PT activity

(i) DNA binding by DndCDE with mutation of cysteine residues on DndC. The green color marks the accidental introduction of an arginine residue mutation in DndD.

(ii) DNA binding by DndCDE with the site directed mutation on DndC or DndD.

(iii) HPLC traces showing DNA PT modification by DndD R217 mutant. The columns show the percentage of PT modification in DndD R217 mutant relative to the wild-type.

Fig 4. DNA PT modification at the GTTC side

(A) HPLC traces showing PT reaction with substrate DNA containing one PT modification. Substrate 1 contained a dGsA modification. Substrate 2 contained a dGsT modification. PT modification on the opposite side was then analyzed using HPLC/MS. For example, for substrate 1, dGsT was analyzed.

(B) EMSA analysis of DndCDE binding to ds DNA with PT modification at one strand. Substrate DNA florescence is indicated by green color. Cold DNA is indicated with gray color. Ten- or twentyfold more unlabeled cold DNA was used for the experiments.

(C) CD spectra of DndCDE protein binding to DNA with PT modification at one of the ds strands.

Fig 5. Effects of small molecules on DndCDE conformation and DNA complexation

This article is protected by copyright. All rights reserved 
In these experiments, $1 \mathrm{mM}$ (if not indicated specifically) small molecules were used. In addition, $3.38 \mu \mathrm{M}$ DndCDE and $0.4 \mu \mathrm{M}$ DNA were used in the EMSA study.

(A) EMSA analysis of DndCDE binding to substrate DNA in the presence of ATP, ADP, AMP, (2.5, 5.0 and $7.5 \mathrm{mM}$ respectively) and $\mathrm{ADP} \bullet \mathrm{AlF}(7.5 \mathrm{mM})$.

(B) EMSA analysis of DndCDE binding to substrate DNA in the presence of cysteine $(0,1$ and $2 \mathrm{mM})$ and SAM (0-6 mM).

(C) CD spectra of DndCDE in the presence of ATP, Cys, and SAM. DndCDE $(0.2 \mu \mathrm{M})$ in CD buffer was used for the study.

Fig 6. Pathway for the formation of PT

Small molecules are indicated by squares. Proteins are indicated by round corner squares. The perthiyl radical is indicated by the green dot. The dashed arrows indicate the suggested chemical steps that need to be investigated.

This article is protected by copyright. All rights reserved 
A
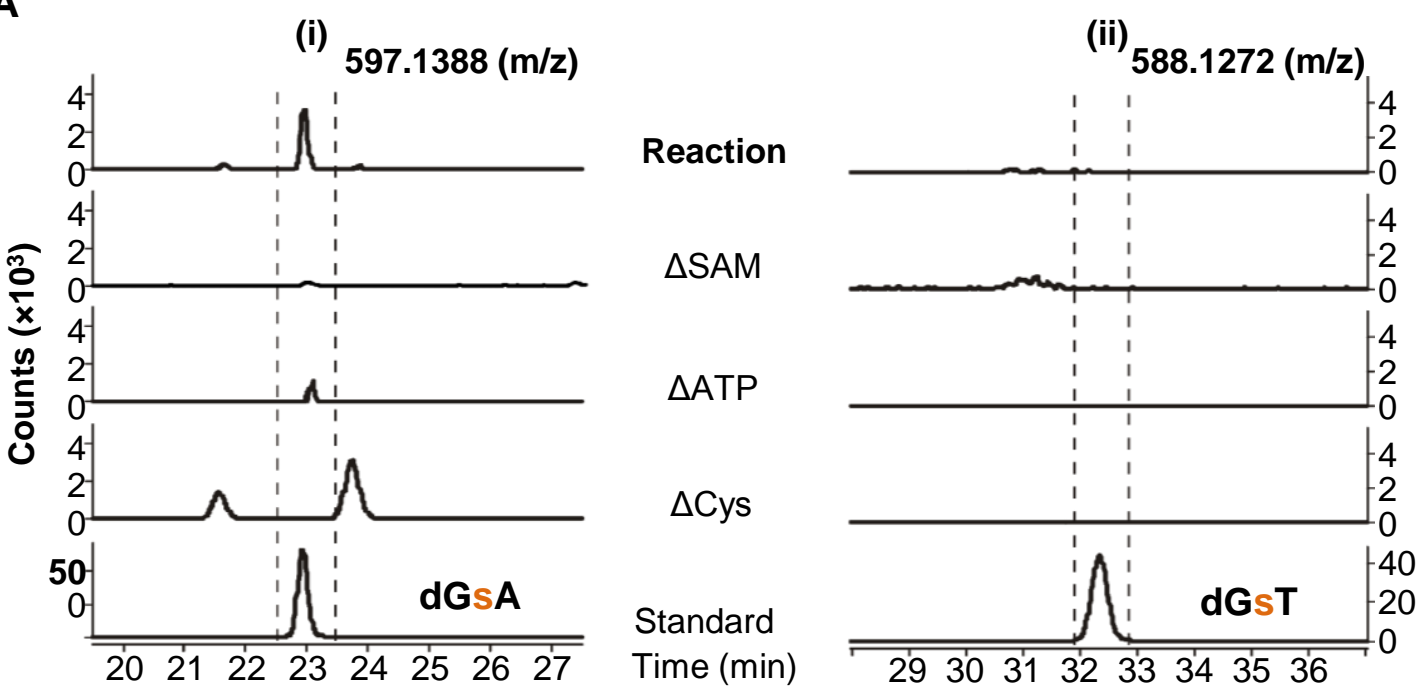

B
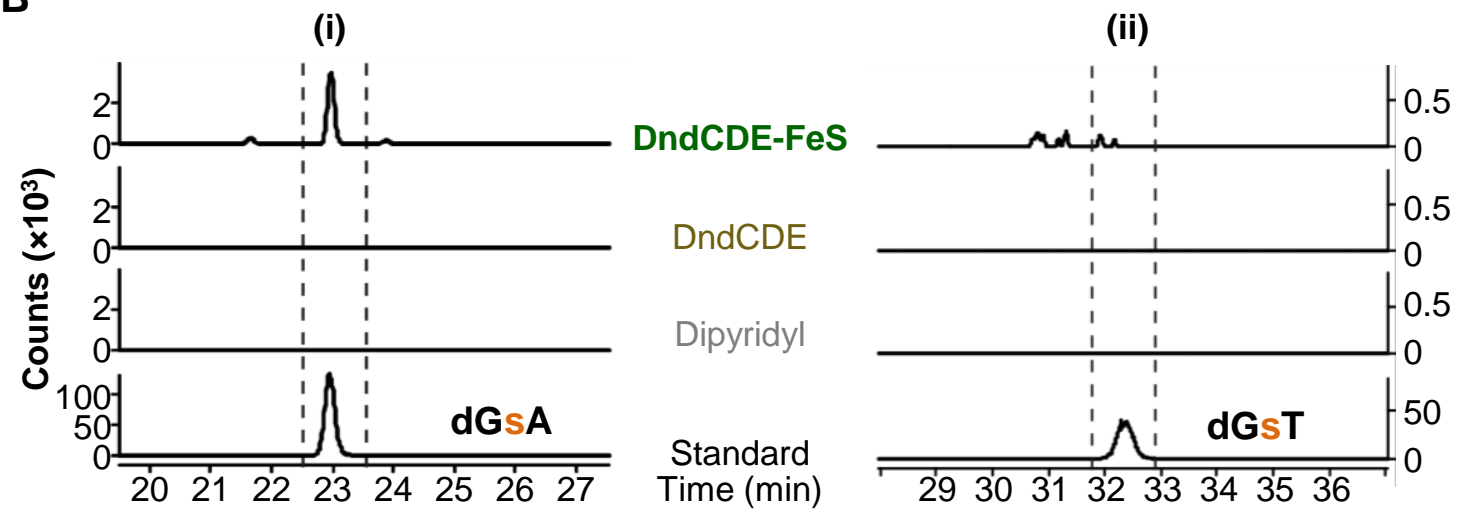
A

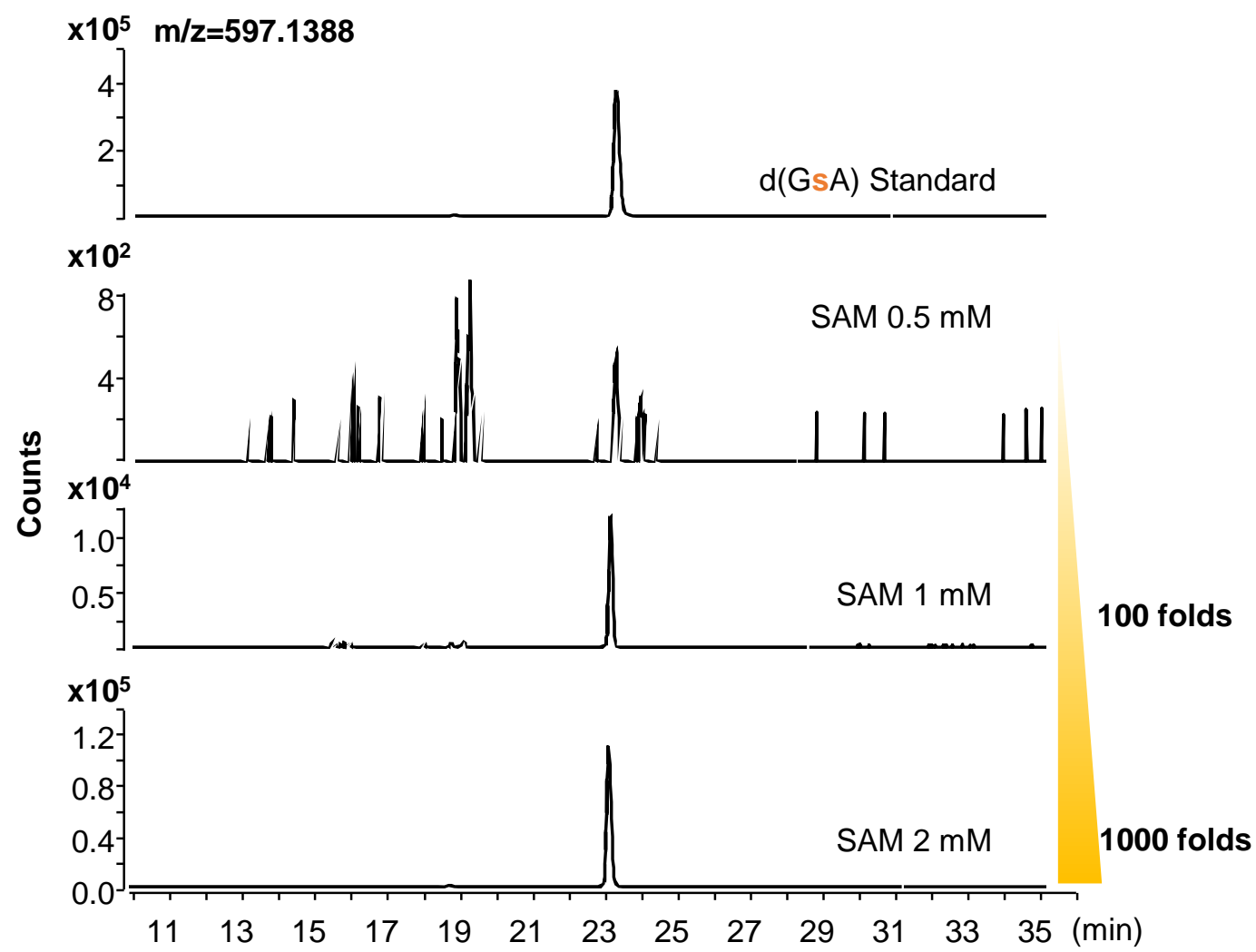

B

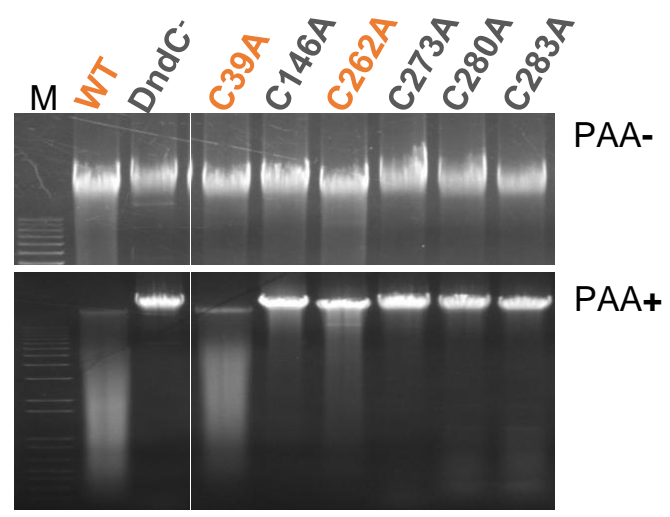

C

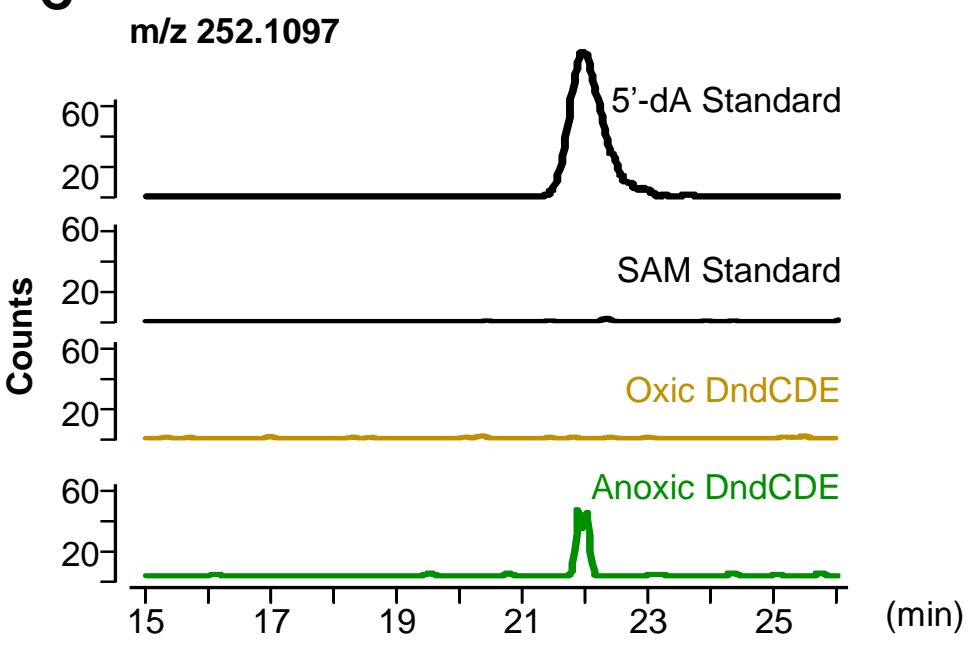


A

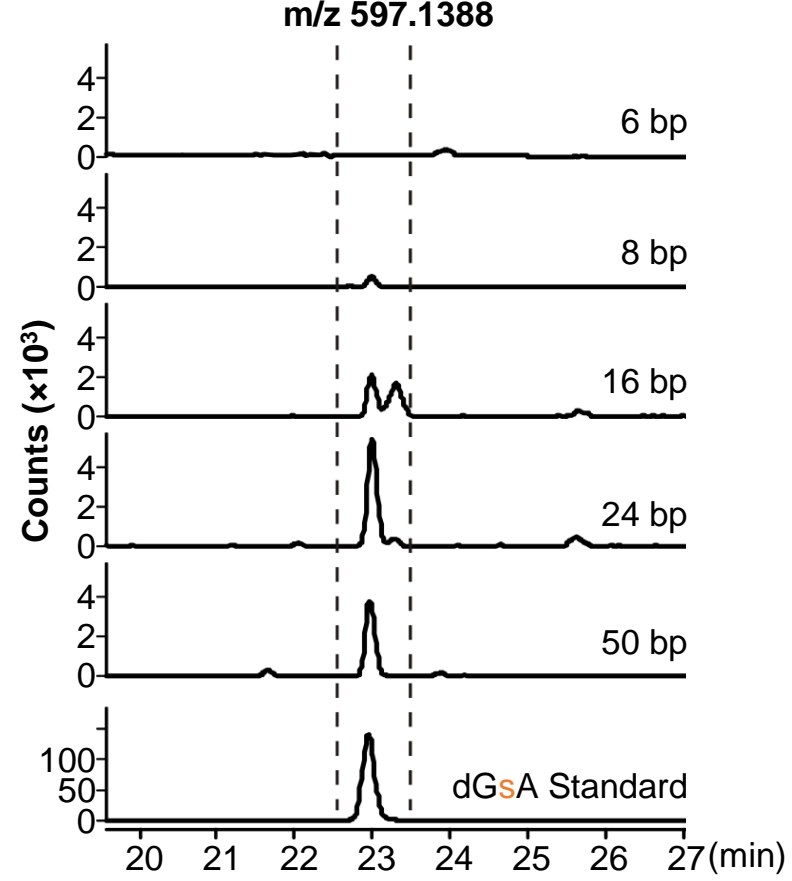

B
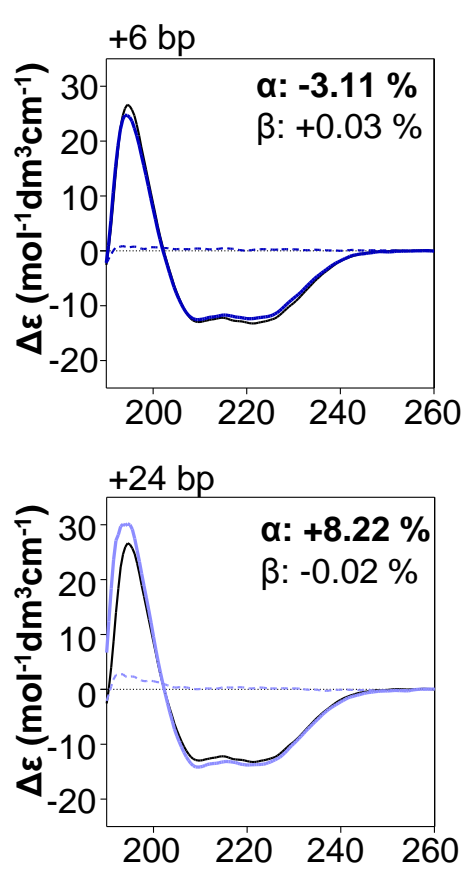
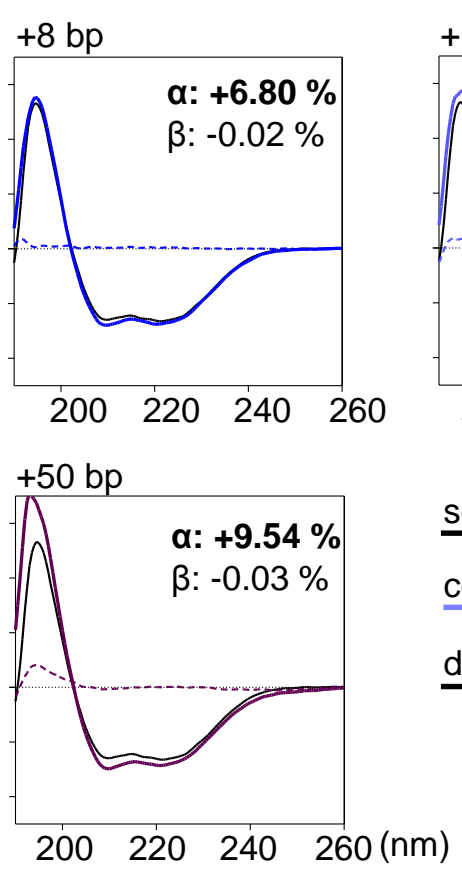

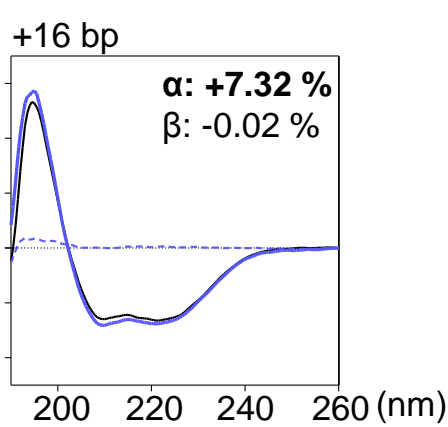

solid DndCDE

color DndCDE/DNA

dash DNA
C DndCDE $\frac{16 \mathrm{bp}}{-+} \frac{18 \mathrm{bp}}{-+} \frac{20 \mathrm{bp}}{-} \frac{24 \mathrm{bp}}{-+}$
D (i) (i) (ii) (iii)
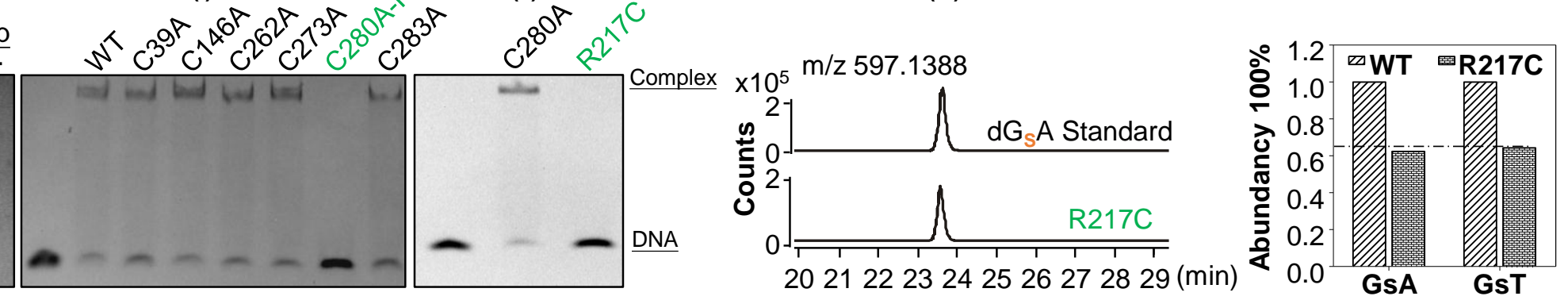
$\mathrm{x} 10^{2}$

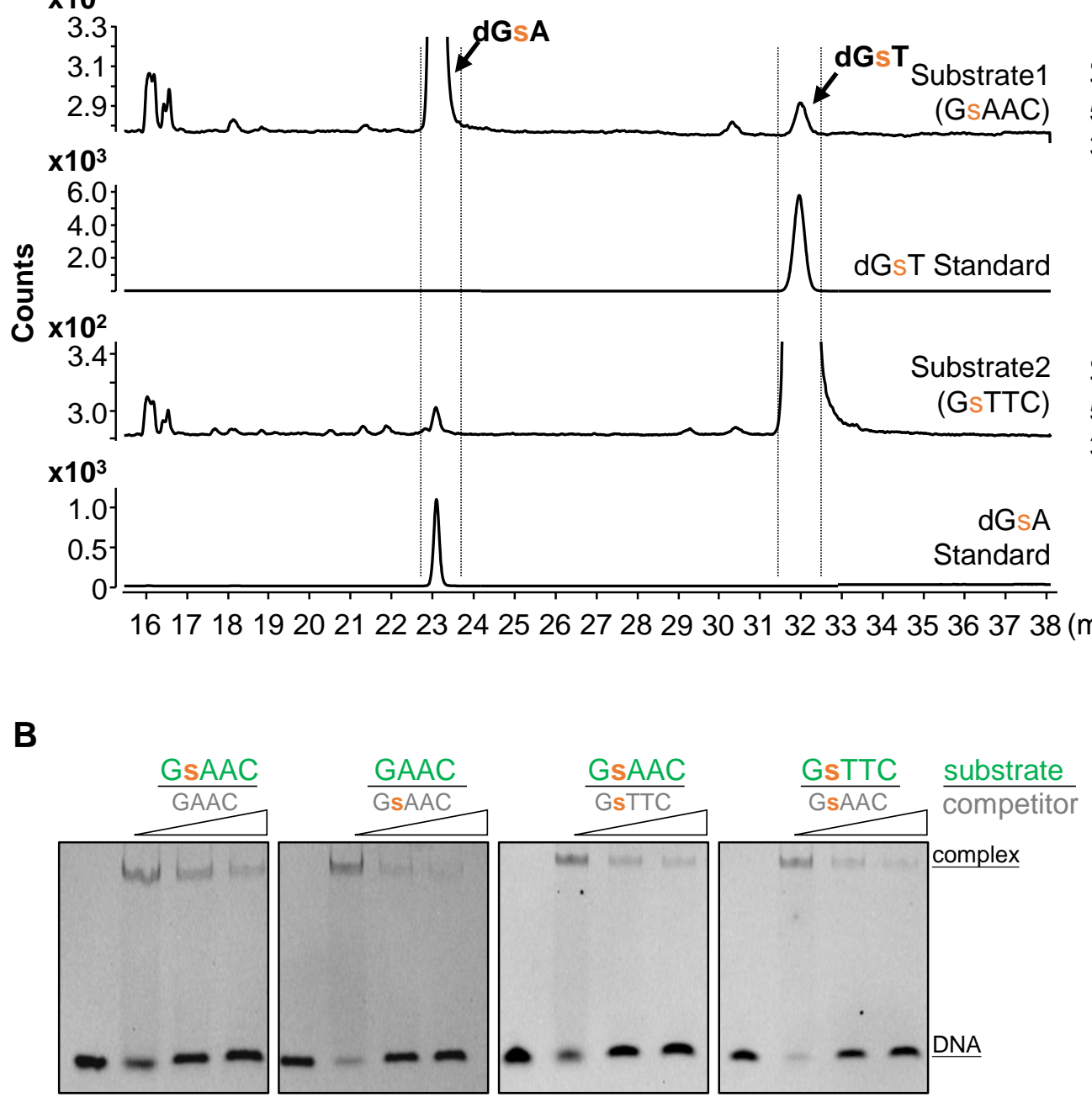

Table 2 Concentration of product (GsA or GsT)

Substrate1

5'......TGCGGG $\mathbf{A A C T C T C G . ~}$

3'.......ACGCCCTTGAGAGC.........

Substrate Product

Concentration $(\mu \mathrm{M})$

GoA/GsT

GoA/GoT

Substrate2

5'-.....TGCGGGAACTCTCG ........

3'-......ACGCCCTT GAGAGC.

GsA/GoT

GsT

GoA/GoT

NA
3.7

0.2

A

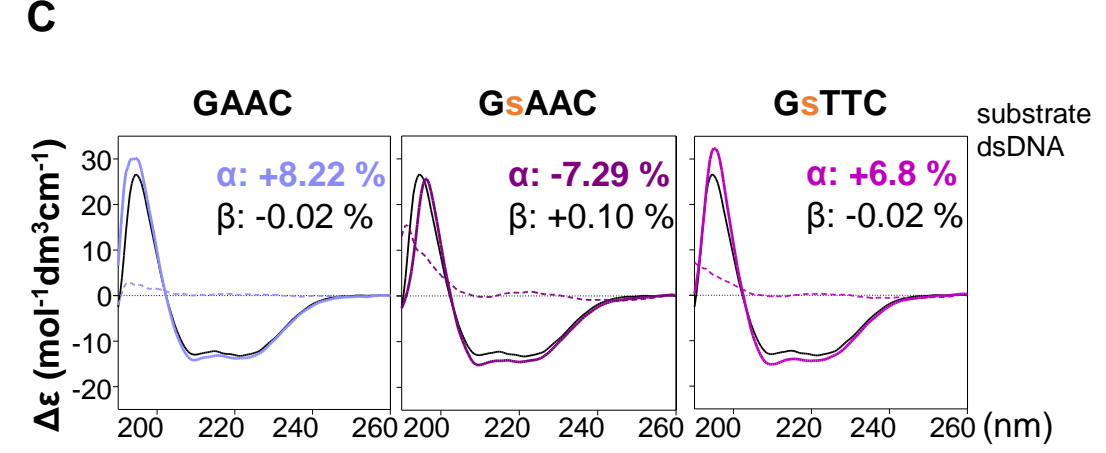




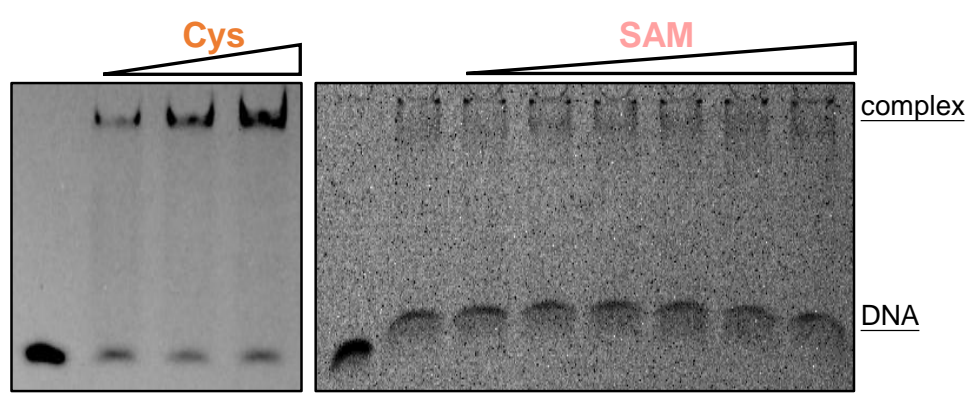

B

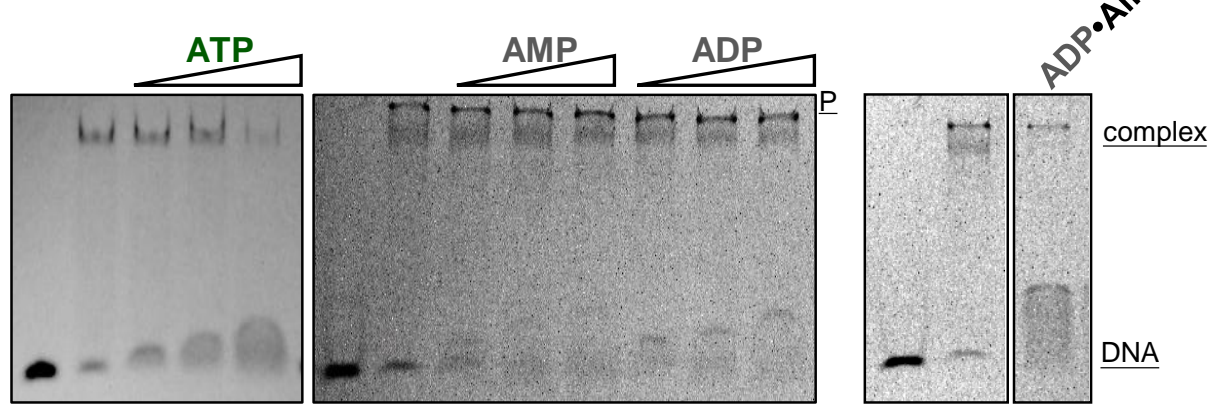

C
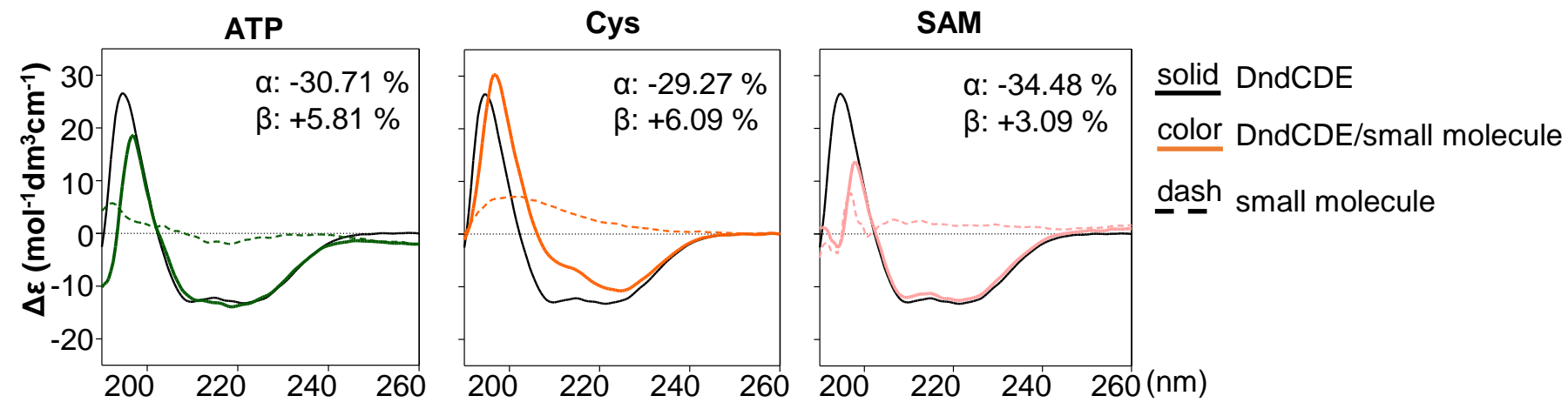


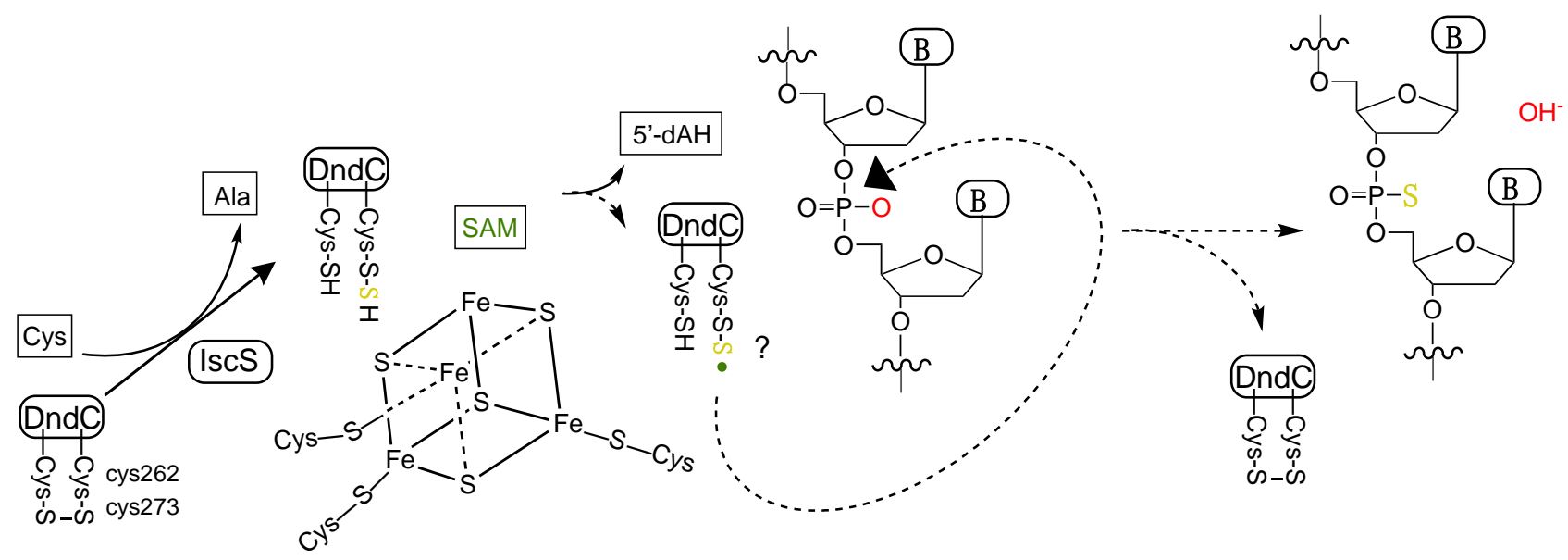

